Marquette University

e-Publications@Marquette

Spanish Languages and Literatures Research and

Languages, Literatures and Culture Faculty

Publications

Research and Publications

8-1-2014

'Un país casi extranjero': Nación, Civilización y Frontera en las Crónicas de Viaje de Manuel Payno

Pilar Bellver

Marquette University, pilar.bellver@marquette.edu

Accepted version. Hispanic Research Journal, Vol. 15, No. 4 (August 2014): 302-317. DOI. (C) 2014

Maney Publishing. Used with permission. 


\title{
'Un país casi extranjero': nación, civilización y frontera en las crónicas de viaje de Manuel Payno
}

\author{
Pilar Bellver \\ Department of Foreign Languages and Literatures \\ Marquette University \\ Milwaukee, WI
}

\begin{abstract}
A pesar del creciente interés en la literatura de viajes sobre México, son muy pocos los estudios que exploran el modo en que los propios autores mexicanos se sirven de este género para crear y definir la nación tras la independencia. Este artículo analiza 'El Río Bravo del Norte', una serie de crónicas publicadas por Manuel Payno sobre sus viajes por las entonces llamadas 'Provincias Orientales' en los años inmediatamente anteriores a la guerra con los EE.UU. Haciéndose eco de la visión del norte como territorio desértico y salvaje que caracterizó el imaginario cultural colonial, Payno presenta la frontera como un espacio que debe ser domesticado con el objetivo de asegurar la prosperidad e integridad territorial de la joven república. Payno convierte la frontera en escenario de una renovada misión civilizadora que erige la capital y sus élites en paradigma de la modernidad. El modo en que esta utopía de modernización determina la representación de la historia, el paisaje y las gentes del norte en las crónicas de Payno constituye el tema central de este artículo.
\end{abstract}

Palabras Clave: Manuel Payno, literatura de viajes mexicana, literatura mexicana siglo XIX, literatura fronteriza, paisajismo, costumbrismo

Hispanic Research Journal, Vol 15, No. 4 (August 2014): pg. 302-317. DOI. This article is @ Maney Publishing and permission has been granted for this version to appear in e-Publications@Marquette. Maney Publishing does not grant permission for this article to be further copied/distributed or hosted elsewhere without the express permission from Maney Publishing. 
En 1839 el escritor e historiador mexicano Manuel Payno (18101894) recorre los territorios colindantes con la recién creada República de Texas, aprovechando su estancia en la region como funcionario de aduanas del gobierno. Sus impresiones de este viaje y del paisaje, la historia y las costumbres de la zona fueron recogidas en diversos artículos que, bajo el título general de 'El Río Bravo del Norte', se publicaron en uno de los periódicos más emblemáticos de la época, El Siglo XIX, entre los años 1842 y $1843 .^{1}$

Payno comienza su carrera política y literaria en el norte fronterizo mexicano. Cabe imaginar que el entonces joven escritor vive allí experiencias que contribuyen a forjar importantes alianzas ideológicas, tanto como a configurar las imágenes y el vocabulario de su futuro repertorio estético. Mas el valor de estos textos no radica exclusivamente en arrojar luz sobre la génesis de las ideas políticas y literarias de esta importante figura. Tal y como propone Belem Clark de Lara, con estos artículos Payno se inicia en el género de la crónica, género que resulta fundamental para entender el modo en que las élites políticas e intelectuales mexicanas definen la singularidad cultural y geográfica de la nación tras la independencia (2005: 330). Payno es además el primer escritor mexicano que trata de definir e incorporar el norte y la idea de frontera al imaginario cultural de la nueva nación. El espíritu nacionalista de estas crónicas no se manifiesta solamente en la afirmación de lo mexicano frente a lo extranjero, sino sobre todo en el deseo de dar a conocer las entonces llamadas 'Provincias Orientales' y de incorporarlas al proyecto constitutivo nacional.

Este artículo se propone examinar la representación del norte y su frontera en el imaginario político y cultural del México postindependencia a partir del análisis literario de las crónicas periodísticas de Manuel Payno. Cuando Payno escribe estos artículos, la frontera es todavía un concepto impreciso, más cercano a la idea colonial de territorio salvaje que al concepto moderno de límite internacional entre dos naciones soberanas. La propia idea de nación no pasa de ser un proyecto en construcción que amenaza con desintegrarse en un clima de profunda división ideológica, tensiones regionales y amenazas exteriores (Anna, 1998: 22). En este contexto, Payno representa la 
franja norte de México como una tierra virgen, un paisaje vacío de cultura y civilización que debe ser transformado o colonizado con el fin de traer prosperidad a la región, y de fortalecer así la frágil armazón institucional y territorial de la nueva república. En una maniobra retórica cuyos antecedentes pueden rastrearse hasta las crónicas del descubrimiento, Payno convierte la frontera en escenario de una utopía de modernización. En esta utopía, el emergente estado mexicano se describe como agente de la civilización; el desierto norteño y sus habitantes se convierten en metáfora de los obstáculos que la nación encuentra en su camino al progreso.

Un estudio detallado de la retórica de estos textos permitirá determinar los matices que la clásica dicotomía civilización/barbarie adquiere al recrearse en la literatura mexicana de la época, al tiempo que contribuirá a establecer la influencia que los marcos de interpretación coloniales ejercen en el discurso nacionalista postindependencia. El análisis de la representación del norte y sus fronteras ayudará a su vez a iluminar el modo en que la descripción de diferentes paisajes y costumbres regionales permite a las élites intelectuales de la época elaborar un imaginario nacional que busca dar cohesión a una sociedad profundamente heterogénea, pero que acaba legitimando la hegemonía política y cultural de los grupos vinculados a la capital.

La crónica es uno de los géneros más representativos del siglo XIX mexicano. En su definición más básica, la ofrecida por el diccionario de la Real Academia, la crónica es un 'artículo periodístico sobre temas de actualidad'. Aunque el término tiene sus raíces en la época colonial, su reaparición, transformación y desarrollo en el siglo XIX están ligados a la influencia de los cuadros de costumbres que se popularizan en la prensa francesa y Española desde mediados de siglo, y que fueron emulados con avidez por los escritores mexicanos más representativos del momento. La crónica de viajes es un subgénero híbrido y peculiar, ${ }^{2}$ pues combina la inmediatez de la prensa y el espíritu realista del costumbrismo con la intensidad metafísica del relato de viajes romántico popularizado por los viajeros europeos de principios de siglo. En lugar de buscar inspiración en lugares exóticos o extranjeros, el cronista mexicano convierte el viaje en vehículo de reflexión sobre la propia identidad (Pitman, 2008: 49). Tal y como el 
mismo Payno expresa, la crónica permite ofrecer una visión mexicana de los principales asuntos que conciernen al país, 'sin aguardar a que los extranjeros vengan a enseñarnos lo que hay en nuestro propio suelo' (1996a: 71). El género tiene además una importante dimensión didáctica y cívica. Su propósito, explica Payno, es educar a la población respecto a la 'cultura, belleza y civilización de otros departamentos de la República', y superar así un provincialismo que amenaza la integridad del proyecto republicano al ocasionar 'que los individuos vean todo lo que no es de su país con cierta indiferencia' (1996a:101). El deseo de construir la identidad desde un punto de vista mexicano y de estrechar los vínculos 'imaginados' entre los habitantes de la nación se convierte para el escritor en la motivación principal para la asidua práctica del género.

Las crónicas de Payno publicadas bajo el título "El Río Bravo del Norte" dejan constancia de un viaje realizado desde la ciudad de Matamoros a las principales localidades situadas en los márgenes de la nueva e imprecisa demarcación territorial establecida con Texas (Reynosa, Camargo, Mier, Revilla, Lerdo y otros lugares cercanos). En esta época, el norte, como el resto del país, es una región convulsa. El recrudecimiento de las guerras con los grupos indígenas, y el colapso del sistema de presidios y misiones ante la interrupción de la llegada de fondos del gobierno central han frenado el desarrollo de la región tras la independencia. Por otro lado, el levantamiento de las restricciones coloniales sobre el comercio exterior ha comenzado a estimular el crecimiento de los intercambios con EE.UU. y, con ello, el poder y el deseo de autonomía de las élites locales, dando lugar tanto a luchas intestinas por el control de las instituciones regionales como a diferentes rebeliones secesionistas (Truett, 2006: 29). EE.UU., por su parte, continúa consolidando su política de expansión hacia el oeste. La independencia de Texas no sólo ha puesto de manifiesto el fracaso de la política de repoblación en el norte, sino que ha convertido en realidad el fantasma del desmembramiento territorial, y ha abierto el camino a una posible guerra con el país vecino. La falta de control sobre los lejanos territorios de la frontera septentrional ha pasado de ser un problema de ámbito local a una cuestión que afecta la consolidación y la prosperidad de toda la nación.

Hispanic Research Journal, Vol 15, No. 4 (August 2014): pg. 302-317. DOI. This article is @ Maney Publishing and permission has been granted for this version to appear in e-Publications@Marquette. Maney Publishing does not grant permission for this article to be further copied/distributed or hosted elsewhere without the express permission from Maney Publishing. 
En este contexto, Payno aborda la escritura de sus viajes por el norte principalmente como una cuestión política. Su propósito al escribir estas crónicas es, sobre todo, concienciar a la opinión pública y a la clase política mexicana del peligro que entraña continuar dejando esta región desatendida. Tal y como el autor explica en diferentes momentos de la narración, el desaprovechamiento de los recursos mineros, la asfixia del comercio legal por leyes aduaneras anticuadas que acaban redundando en el crecimiento del contrabando, y el abandono de la menguante población al acoso de 'indios' y bandidos que recorren ambos lados de la frontera son los principales factores que desestabilizan la economía de la región. Es más, Payno recorre los territorios fronterizos bajo la sombra de la guerra con los EE.UU., y es testigo de las constantes escaramuzas y enfrentamientos entre ambos ejércitos que se dieron en esta zona en los años que precedieron la declaración de la estadía de Texas. El propio título utilizado por el escritor para englobar sus crónicas, 'El Río Bravo del Norte', apunta a la doble naturaleza económica y territorial del conflicto, pues en esos momentos ambos países reclaman jurisdicción sobre el río dado su valor estratégico y comercial. ${ }^{3}$ Pese a sus convicciones liberales y su admiración por el modelo político que representan los EE.UU., Payno acaba asumiendo frente a este país una postura defensiva, y propone el desarrollo económico y demográfico de la región fronteriza como única manera de salvaguardar la soberanía de la nación. Es por ello que en 'La costa', el segundo artículo que publica sobre estos viajes, Payno concluye enfático:

Nuestros enemigos velan, y nosotros dormimos; ellos conocen que el río Bravo es un tesoro, y nosotros lo despreciamos [...] El norte es un torrente que amenaza sorber nuestras posesiones. Es menester un dique. Este dique es un aumento de la población, unas sabias leyes comerciales que hagan que los extranjeros pisen nuestras playas, no como avaros especuladores, sino como unos amigos a quienes brindamos con nuestro carácter afable, nuestra naturaleza virgen, y nuestro purísimo cielo, a que se establezcan y vivan entre nosotros. (Payno, 1996a: 41)

Las crónicas de Payno sobre el norte manifiestan un claro espíritu emancipador en lo tocante al aprovechamiento y protección de los propios recursos. Estos artículos introducen además una voz mexicana en la literatura de viajes de la época, un género dominado hasta el

Hispanic Research Journal, Vol 15, No. 4 (August 2014): pg. 302-317. DOI. This article is @ Maney Publishing and permission has been granted for this version to appear in e-Publications@Marquette. Maney Publishing does not grant permission for this article to be further copied/distributed or hosted elsewhere without the express permission from Maney Publishing. 
momento por autores europeos. No obstante, sería un error considerar que las críticas lanzadas a los EE.UU. testimonian la aparición de un incipiente discurso antiimperialista que define la singularidad de la nación por oposición con la del país vecino; o que, dada la perspectiva mexicana desde la que se enuncian, estos textos representan la aparición de un nuevo fenómeno cultural que rompe con los marcos de interpretación que le preceden. Tal y como nos recuerda Pitman, el desarrollo de la literatura de viajes como género está íntimamente ligado al proceso de expansión colonial, y la crónica mexicana imita abiertamente modelos románticos europeos (2008: 40). Según Pitman, el manifiesto deseo entre los intelectuales mexicanos por seguir estos modelos resulta en una criollización del género, es decir, una adaptación que no llega a cuestionar el origen ideológico de sus estructuras discursivas ni la idoneidad de reproducirlas en un nuevo contexto. La reinvención o transculturación sistemática de los tropos que caracterizan la literatura de viajes europea no se dará hasta fines de siglo $X X$, cuando se recurra a técnicas posmodernistas para ironizar sobre sus problemáticas asociaciones imperialistas (82-84). ${ }^{4}$

Payno es frecuentemente descrito como un liberal moderado. La historiadora Nicole Giron lo califica de 'liberal en tono menor' y lo define como un intelectual de transición, dividido entre el deseo de cambio y la nostalgia de lo que se deja atrás (1994: 32-33). En un sentido amplio, Payno pertenece a lo que Walter D. Mignolo ha denominado 'la primera generación de intelectuales postcoloniales' latinoamericanos (1995:183). Según Mignolo, cuando estos se lanzan a la tarea de narrar la nación tras la independencia, los marcos de referencia que se habían utilizado para definir el continente hasta ese momento no se desechan. En su reciente Local Histories/Global Designs, Mignolo expande esta idea y afirma que la mirada europeizante de la intelectualidad post-independencia latinoamericana se inserta en una tradición epistemológica occidentalista que concibe América como una extensión de Europa - su 'extremo occidental' - y no como su opuesto, papel que se reserva para el Oriente. Desde esta perspectiva, las élites latinoamericanas del momento no sólo se caracterizan por su deseo de emular a Europa, sino que se ven a sí mismas como 'leaders of a civilizing mission in their own country' (Mignolo, 2000: 55-58). 
En Latinoamérica, la idea de nación nace así inextricablemente unida a la de modernización, dando lugar a una dialéctica entre atraso y progreso que no sólo afecta al modo en que la nación se define respecto a Europa, sino también a la manera en que las élites reconfiguran su relación con la heterogénea realidad local. Es por ello que, pese a la amenaza que representan, la idea de nación recreada por Payno en estas crónicas no va a pivotar todavía sobre la oposición a los EE.UU., un país de raíces culturales occidentales y admirado además por haber sido capaz de diseñar un modelo efectivo de organización política postcolonial. El verdadero otro de la nación será todo aquello que dentro del propio país ponga obstáculos a la consolidación del proyecto nacional, es decir, todo aquello que impida a México llegar a convertirse en una nación plenamente moderna, y ser percibida como tal. Es por ello, a su vez, que en estas crónicas viajar y escribir sobre la frontera norte equivaldrá a integrar un espacio desconocido en las coordenadas conceptuales del archivo cultural europeo. El norte se convertirá así en una página en blanco, un espacio de la imaginación en el que las peculiaridades de la realidad local se subordinarán al proyecto civilizador que inspira a su autor.

El deseo de extender la civilización dentro de la propia nación es precisamente la idea que articula las crónicas de Manuel Payno sobre el septentrión. En esta renovada 'misión civilizadora', la autoridad de la metrópolis se sustituye por la del emergente estado mexicano, y el norte, al modo de las colonias, pasa a ocupar una territorialidad lejana y periférica, un espacio bárbaro o al margen de la civilización. La dualidad civilización/barbarie no es una creación conceptual decimonónica, y ni siquiera colonial, sino que más bien amalgama una serie de significados y asociaciones que se remontan a la época clásica, y que se filtran en el discurso cultural sobre América a partir de la conquista. El término barbarie aparece por primera vez en el griego asociado a la idea de lenguaje y significa 'to speak broken Greek, to speak gibberish' (Liddle \& Scott, 1961: 306). En su contexto clásico, el concepto de barbarie no implica necesariamente una diferencia racial o étnica, sino un estadio primitivo de competencia que puede encontrarse tanto dentro como fuera de la propia cultura, y que es susceptible de remediarse (Losada, 2009: 5). Por su parte, el término civilización no aparece en su acepción actual hasta bien entrado el siglo XVIII. A partir de la Ilustración, explica el politólogo 
Brett Bowden, la idea de civilización es indisociable de la noción de progreso, y se utiliza tanto para describir como para evaluar, tanto para celebrar un determinado estándar político e intelectual como para condenar a aquellos grupos o culturas que supuestamente no han alcanzado un grado suficiente de evolución (2009: 8).

Esta idea de civilización como progreso y de barbarie como estado de inmadurez cultural informa las propuestas de Payno sobre el norte y articula la perspectiva desde la que se escriben sus crónicas. Payno narra sus viajes desde una posición de autoridad. Aunque sus textos carecen de carácter oficial, el escritor ha llegado al norte en calidad de representante del gobierno. Según él mismo expresa, y dados los inconvenientes que conlleva viajar por lugares 'donde la civilización ha puesto muy poco de su parte', el relato de sus viajes se aborda prácticamente como un deber para con sus conciudadanos: 'Si tantos jóvenes van a Europa [. . .] yo, caminando por los desiertos de mi país, he de formar unas impresiones del viaje que mal o bien indiquen que los objetos no han pasado por mis sentidos sin dejar una impresión' (1996a: 59-60).

Esta posición de autoridad se establece ya en la descripción que abre la serie. Payno elige comenzar su narración situando la mirada del viajero sobre la azotea de una casa del puerto de Matamoros. Desde allí, su mirada recorre la ciudad y sus alrededores, y llama nuestra atención sobre diferentes detalles: una laguna limitada por 'una cinta de bosque amarillento', un río que 'se asemeja a una cinta de agua turbia, y al parecer inmoble', 'jacales miserables de techo de palma'. En este panorama desolador tan sólo resaltan por su solidez los escasos 'edificios de construcción americana' (1996a: 33). De ahí que el narrador se lamente a modo de conclusión: 'La civilización está invadiendo como en los más de los pueblos americanos, y desterrando los usos y las construcciones primitivas; pero allí, más que en otra parte, se hace notar eso, pues ni la fisonomía ni las casas, ni aun los habitantes, se parecen a ninguno de los demás pueblos del interior' (33).

En primer lugar, con esta descripción, Payno establece una distancia emocional respecto a lo narrado que convierte el norte en un objeto susceptible de ser interpretado y valorado. De hecho, al ubicar la 
mirada del observador en una azotea, Payno reproduce lo que tanto Mary Louise Pratt como David Spurr, en sendos análisis del funcionamiento de la retórica del descubrimiento en la literatura europea de exploración y colonización, identifican como una de las modalidades más comunes del discurso de apropiación colonial: la visión panorámica. ${ }^{5}$ En la panorámica, explican los autores, el observador se sitúa física y mentalmente en una posición de dominio que subordina lo observado a su propio sistema de valores, imbuyendo el espacio de significados ideológicos (Pratt, 1992: 204-06, Spurr, 1993: 15-16). En su análisis de la pervivencia de esta retórica colonial en el periodismo literario de los siglos XIX y XX, Spurr precisa que la posición de distancia desde la que habla el observador crea además una apariencia de imparcialidad que enmascara la dimensión histórica del texto, y que acaba desplazando al propio sujeto colonizado el deseo de apropiación que impulsa la obra (28).

Al analizar la cultura visual mexicana de la época, Erica Segre identifica también la panorámica como una de las técnicas pictóricas más comúnmente empleadas para retratar la capital del país. Según Segre, la representación de la ciudad desde balcones y azoteas permite mostrar una imagen idealizada de la urbe mexicana, al enfatizarse el orden y simetría de su diseño en un periodo caracterizado por la sensación de caos creada por continuos cambios de gobierno (2007: 37). En el caso de Payno, lo que resalta en la panorámica de Matamoros no es la idea de orden sino la falta de vitalidad, algo que se refleja tanto en la ausencia de habitantes como en los adjetivos que califican el paisaje: 'amarillo', 'turbio', 'inmoble', 'miserable'. En Matamoros, el paisaje natural apenas se diferencia del urbano, anticipando la falta de progreso y organización política que aqueja la región. El aspecto desolado de la ciudad se convierte así en una forma de justificar la política de Payno respecto la frontera. El imperativo político de repoblar e impulsar el desarrollo comercial de la región se transforma en un deber cívico, una forma de paliar la miseria o falta de civilización en la que se encuentra sumida la región.

La posición de autoridad que se establece con la visión panorámica transforma también la realidad humana de la frontera en un sujeto carente de voz (Spurr, 1993: 13). No resulta por ello sorprendente que Payno no incluya en estas crónicas testimonios 
directos de los habitantes del lugar, bien en forma de diálogos o a la manera de relatos orales transcritos. De hecho, esto sólo ocurre cuando lo escuchado tiene un contenido que hoy se podría calificar de truculento o sensacionalista, como la historia de una joven que conoce en un recóndito rancho y que relata cómo lleva consigo a todas horas un puñal para matarse en caso de ser capturada por los 'indios bárbaros' (Payno, 1996a: 73-76). En lugar de hacer visible el punto de vista local, historias como esta vienen a reforzar los estereotipos existentes sobre el norte como un país sin control, y buscan la empatía del lector respecto a la tesis central del autor sobre la necesidad de una mayor presencia del gobierno republicano en la región.

Por otro lado, en sus frecuentes comentarios políticos sobre las necesidades de estas provincias el escritor tiende a relegar el protagonismo de las élites locales a un plano secundario de significación. Payno conoce de primera mano la problemática secesionista en la región. Durante su estancia en Matamoros, y tras abandonar su puesto de funcionario de aduanas, el escritor trabajó como asistente personal del general Mariano Arista, a la sazón comandante del Ejército del Norte y encargado de sofocar o negociar el fin de la mayoría de estas rebeliones. De hecho, Payno dedica una de sus crónicas al análisis político de los levantamientos en la zona, y a proponer soluciones que a largo plazo puedan estabilizarla. ${ }^{6}$ Mas, en el relato de sus viajes, esta historia local se diluye en una historia nacional que integra la trayectoria del norte en una narrativa universal de progreso que comienza con la conquista. Por ejemplo, al resumirse la historia de Tamaulipas leemos:

Concretando [. . .] Tamaulipas antes de la Conquista era un desierto, después [. . . ] un desierto dominado por tribus bárbaras; bajo la dominación de los virreyes, unas colonias o presidios mandados por sus respectivos capitanes [. . .] y bajo la República, un estado libre y soberano. Así, los aduares de las tribus fueron reemplazados por las chozas de los colonos, y las chozas por las decentes habitaciones de los ciudadanos [. . .] El tiempo vendrá y estas ciudades serán hermosas y ricas, porque la progresión de la vida de los hombres y de los pueblos está marcada de una manera inmutable. (Payno, 1996a: 69) 
Payno escribe estas crónicas en una época turbulenta. Al analizar el papel de la prensa mexicana en estos años, Erica Segre afirma que una de las principales preocupaciones de los intelectuales que publicaron regularmente en la prensa cultural fue inculcar en sus lectores un sentido de unión que propiciara la creación de un ambiente social conducente a la consolidación del proyecto nacional tras la independencia (2007: 6). Las crónicas de Payno sobre el norte se adscriben plenamente a esta filosofía, y proponen unificar al país en torno a una narrativa de progreso. Tal y como demuestra la cita anterior, en estos textos el espíritu de revolución que impulsó a los intelectuales a la lucha por la independencia deja paso a la idea de evolución, ${ }^{7}$ concepto que se manifiesta tanto en la progresiva mejora de las viviendas de los habitantes norteños como en lo que Payno interpreta como un paulatino perfeccionamiento de las instituciones de control y gobierno que operan en la región. La misión civilizadora que articula estas crónicas permite así relativizar los aspectos más conflictivos de la realidad local. Al representarse la historia de las provincias orientales como parte de un proceso universal e imparable de modernización, estas crónicas minimizan el impacto histórico de estas rebeliones regionales, al tiempo que se enfatiza la necesidad de unión de las élites en torno a un proyecto común de progreso.

En segundo lugar, es obvio al analizar la descripción con la que se abren las crónicas que, para Payno, Matamoros se encuentra todavía en un estadio evolutivo inferior. Esta falta de progreso hace difícil relacionar culturalmente la ciudad con lo que el escritor denominaba al comenzar su relato 'los demás pueblos del interior' (1996a: 33). De hecho, las referencias al 'interior' abundan en estos textos, siempre en contraste con la sequedad y la miseria del norte, y siempre imbuidas de nostalgia. Por ejemplo, al relatar las penalidades que conlleva atravesar el desierto, el narrador recuerda su grata vida en la capital casi como una alucinación dolorosa: 'A las once el calor se hacía sentir con fuerza [. . .] los árboles del bosque parecía que giraban entre llamas; a veces veía yo correr arroyos de agua cristalina; a veces creía encontrarme en medio de un corrillo de amigos en los salones espléndidos de México [. . .] iOh, qué terribles recuerdos!' (1996a: 72). En otra ocasión, y abrumado por las incomodidades y la pobreza que encuentra en Mier, el narrador se deja llevar por un 'sueño hermoso' en el que recorre los alrededores de la 
capital en un día de Pascua, y del que despierta exclamando: 'iHorrible transición! Pasar súbitamente [. . .] desde San Francisco de México a un jacal de la frontera' (57).

Payno se aproxima al norte desde una perspectiva capitalina. Pese al carácter federalista de la constitución de 1824 , y pese a la autonomía que los políticos liberales como él reconocen para las provincias, a mediados del siglo XIX el peso político y económico del centro y de sus élites es indiscutible. El interior, tal y como lo describe el historiador Timothy Anna, es 'a network of accumulated economic, political, financial, and intellectual power located in the Valley of Mexico' (1998: 102). El Valle Central y la capital albergan un 20\% de la población total del país y juntos representan un tercio de su riqueza (Anna, 1998: 102). La capital, de hecho, gana peso político e influencia al federalizarse y separarse del estado de México, pues sus élites pasan entonces a concentrar sus recursos y esfuerzos en el objetivo de convertirse en la base de poder de la nación (1998: 195).

Es obvio que, para Payno, el 'interior' marca además el estándar civilizador mediante el que debe valorarse y juzgarse la sociedad de la frontera. Cabe ahora recordar que tanto la palabra 'cultura' como la palabra 'colonizar' derivan del latín colere, que significa cultivar, habitar o cuidar. Tal y como explica Spurr, en latín la palabra 'colono' se refería al mismo tiempo a la persona que labraba la tierra y al soldado asentado en un territorio recién conquistado; la palabra 'cultura', por su parte, 'referred both to the tilling of the soil and to the refinment in education and civilization' (1993: 5). En el discurso imperialista y colonial, la labranza de la tierra y la conquista y civilización de nuevos territorios son pues actividades estrechamente relacionadas.

Payno se hace eco de esta misma asociación cuando describe el inicio de la actividad agrícola en la región en los siguientes términos: 'Antes de la retirada a Matamoros del ejército de Tejas, casi no se hacían siembras de ninguna clase; pero desde que llegaron a un país casi extranjero una porción de soldados acostumbrados a los alimentos de la gente del campo del interior, las necesidades aumentaron, y los paisanos comenzaron a sembrar sus labores y sementeras de maíz' (1996a: 35). A pesar de que a mediados de siglo XIX el norte es ya 
una sociedad profundamente campesina, el escritor decide mostrar la agricultura como una aportación cultural del interior del país. La integración del norte en el proyecto constitutivo nacional se concibe a nivel simbólico como la transformación de una naturaleza improductiva en un jardín agrícola, y el ejército mexicano, identificado con la cultura y el poder del centro, es el agente encargado de llevar a cabo esta transformación. La misión civilizadora que anima al autor se convierte así en una forma de extender la influencia política y cultural del interior hacia la periferia. En estas crónicas, la capital y sus alrededores se identifican inequívocamente como motores del progreso de la nación. Las provincias del septentrión se van a configurar más bien como su opuesto dialéctico, es decir, como imagen especular de un interior que legitima su pertenencia al elenco de las naciones civilizadas precisamente mediante el contraste con la barbarie norteña.

El proyecto de modernización que subyace a la escritura de estas crónicas se refleja también en el empleo de una serie de tropos que afectan al tratamiento de dos elementos esenciales en la literatura de viajes de la época: la descripción de los paisajes naturales y la caracterización de los habitantes. No en vano, paisajismo y costumbrismo son dos de los motivos más frecuentemente empleados por los artistas mexicanos del siglo XIX para crear y propagar la identidad nacional. ${ }^{8}$ El uso de técnicas paisajísticas románticas se convierte en una forma de delimitar y celebrar la geografía local, equiparándola implícita y explícitamente con la europea (Pitman, 2008, 40). El costumbrismo, por su parte, permite materializar en diferentes tipos humanos los comportamientos que ejemplifican el carácter y la idiosincrasia nacional (French, 2011, 14-15). En estas crónicas, sin embargo, ni el paisaje norteño ni las costumbres de quienes lo habitan provocan alabanzas por parte del escritor. Por el contrario, Payno describe el norte como una geografía física y humana carente de interés o de belleza. Esta descripción reafirma la posición ideológica desde la se aborda la escritura de las crónicas, al presentar el norte como un espacio susceptible de ser embellecido o mejorado por la presencia e intervención del estado mexicano y las culturas del interior. $^{9}$

En primer lugar, para Payno el norte es un desierto. Tal y como el narrador constata al comenzar la narración: 'Ni una rosa, ni una 
amapola, ni un clavel, ni un colibrí, ni un jilguero alegran aquellos terrenos' (1996a: 38). Es necesario matizar que el desierto, más que una realidad geográfica o ecológica, es una metáfora que expresa de forma general una carencia de cultura y civilización. Por ejemplo, al describir su viaje a Reynosa, el escritor comienza afirmando: 'Después de dos horas que pensé apuntar algo en mi cartera, tuve que cerrarla y guardármela en la bolsa. Yo quería escribir; pero [. . . ] nada encontraba digno de contarse. Me puse la mano en la mejilla y dije: recordemos lo que he visto hoy. Salí de Matamoros, volví atrás la cara, y no miré ni cúpulas, ni torres, ni veletas, ni árboles, ni flores' (42). Más tarde, su crónica sobre Mier se enmarca con la siguiente afirmación: 'iqué monotonía de caminos! Todos los días se ven [. . .] los mismos arbustos espinosos, con sus hojas menudas, con su verde sin esmalte; todos los días la misma soledad [. . .] la misma miseria [. . .] Esto no es viajar, no es ver, no es aprender' (55).

En estas crónicas las descripciones del norte como una geografía incapaz de satisfacer las necesidades intelectuales o estéticas del escritor se suceden, inaugurando cada nueva etapa en el camino del viajero. La narración se hace eco así de lo que Spurr define como la estrategia colonial de la negación, 'the rhetorical strategy [. . . ] by which Western writing conceives of the Other as absence, emptiness, nothingness, or death' (1993: 92). De hecho, en el caso de México, la caracterización del desierto norteño como vacío hunde sus raíces en la época virreinal. Tal y como explican Enrique Rajchenberg y Catherine Héau-Lambert (2009), ${ }^{10}$ en los tres siglos que dura la colonia, la ausencia de ricas y poderosas civilizaciones, las continuas hostilidades con los indígenas, y la dureza del clima y el terreno hacen emerger en el imaginario cultural la visión del norte como un espacio que se resiste al proyecto civilizador y misionero europeo. La Gran Chichimeca, tal y como se conoce esta región en la época, es además el espacio nómada por excelencia, opuesto conceptual de un interior urbano y sedentario que amenaza desde fuera el orden ciudadano, y que se convierte en expresión de todo aquello que queda más allá del control o del domino del hombre. ${ }^{11}$

En el caso de las crónicas de Payno, esta resistencia a la civilización se manifiesta sobre todo en la imposibilidad de ajustar la descripción del paisaje norteño a las categorías estéticas popularizadas permission has been granted for this version to appear in e-Publications@Marquette. Maney Publishing does not grant permission for this article to be further copied/distributed or hosted elsewhere without the express permission from Maney Publishing. 
por la literatura de viajes del momento. Pese a su evidente familiaridad con la obra de los viajeros románticos europeos, a quienes cita frecuentemente en estas y otras crónicas, los paisajes del norte no despiertan en el escritor intensas emociones, ni llegan a dar pie a reflexiones poéticas o metafísicas. Cuando esto ocurre, como en la crónica titulada 'Sigue el itinerario', en la que se describe una noche pasada al raso con una brigada de la División del Norte, es la contemplación de las estrellas, y no la del paisaje local, lo que hace caer al escritor en un 'dulce y melancólico éxtasis' (1996a: 73). En estos textos, la contemplación de las planicies desérticas no llega a tratarse como una experiencia sublime o trascendental, tal y como ocurre, por ejemplo, en la obra de Alphonse de Lamartine sobre los desiertos del Medio Oriente, o en las observaciones de Charles Darwin sobre la Patagonia. Las descripciones tampoco recurren al concepto de lo pintoresco, tan en boga entre los viajeros ingleses del momento como una forma de legitimar los paisajes locales, hasta entonces excluidos de un canon centrado exclusivamente en estándares clásicos de belleza. El propio Payno descarta la aplicabilidad al norte de esta noción cuando afirma que, aunque le hubiera sido grato 'escribir un viaje pintoresco', ello le resulta imposible, dada la falta de civilización que caracteriza esta región: 'era de todo punto imposible que de unos países despoblados [. . .] les contara cosas maravillosas y sorprendentes, como el que viaja por esas ciudades europeas donde las ruinas antiguas se veneran, donde las creaciones modernas se admiran' (1996a: 59-60). Por contraste, al escribir sobre las diferentes poblaciones que rodean la capital, Payno afirma complacido: 'Los que viven en el valle de México, puede decirse que viven en un paraíso. Apenas se sale de las puertas de la ciudad, cuando se encuentran calzadas pintorescas de fresnos [. . .] o Tacubaya, con sus magníficos edificios y sus extensas huertas, [. . . ] o San Agustín, [. . .] con sus bosquecillos de manzanos o de peras, y sus campos llenos de flores y mieses' (141). ${ }^{12}$

Es obvio que, para Payno, el desierto es un paisaje al margen de la civilización, entendida como un estadio evolutivo superior propio de las naciones europeas, y que esta ausencia de profundidad histórica y cultural que caracteriza los paisajes norteños hace prácticamente imposible su valoración siguiendo los parámetros estéticos de la época. Es más, tal y como ya se observó al hablar de la primacía 
cultural del interior, para el escritor civilizar es transformar. La naturaleza que describe Payno al hablar de los alrededores de la capital resulta estética precisamente por haber sido modificada por el ser humano. En la cita anterior, los fresnos se disponen en 'calzadas', Tacubaya destaca por sus 'edificios' y sus 'huertas', San Agustín por sus cultivos de frutales y cereales. Según Spurr, la estrategia de la negación permite rechazar aquello que queda fuera de los marcos interpretativos con los que está familiarizado el viajero (1993: 92). Pese a los esfuerzos del autor por integrar la región en el proyecto constitutivo de la nación, la negación artística de los paisajes norteños perpetúa su marginalidad dentro del imaginario cultural mexicano, al reforzarse la idea de que sólo los paisajes del culto y cultivado Valle Central han alcanzado ese estado de evolución que permite al escritor transformar la naturaleza en un paisaje u objeto estético.

La estrategia de la negación se manifiesta también en el modo en el que el escritor caracteriza a los habitantes del desierto. En primer lugar, los indígenas son invariablemente calificados de 'bárbaros' o 'salvajes'. Su aparición en la narración se relaciona típicamente con episodios de violencia contra los colonos, y las observaciones del escritor con frecuencia se hacen eco del terror que inspiran en la población. Aunque es cierto que estos textos no recrean la mitología caníbal que solía envolver las referencia a los grupos indígenas del norte en la prensa y en la literatura de la época (Rajchenberg \& Héau-Lambert, 2009), el escritor se muestra tajante en cuanto a la necesidad de subyugarlos, y no duda en elogiar cualquier tipo de acción militar o violenta emprendida contra ellos. La única ocasión en la que su visión parece suavizarse es al hablar de la tribu de los carrizos, de los que afirma que son 'mansos', 'robustos', y menos crueles (Payno, 1996a: 48-49). No obstante, esta caracterización no busca tanto profundizar en el conocimiento de la realidad indígena como reforzar la hegemonía cultural del interior. Es por ello que los atributos positivos de esta tribu se relacionan a reglón seguido con el hecho de ser 'descendientes de los antiguos aztecas', es decir, ser una tribu sedentaria y haber llegado al norte desde el centro geográfico de la nación, dos rasgos que, desde la perspectiva del autor, justifican su adscripción a un estado evolutivo superior (49). El indígena del norte, como el paisaje desértico del que emerge, se va a permission has been granted for this version to appear in e-Publications@Marquette. Maney Publishing does not grant permission for this article to be further copied/distributed or hosted elsewhere without the express permission from Maney Publishing. 
mostrar en todo momento como uno de los principales obstáculos a la misión civilizadora que representa el nuevo estado mexicano.

Por otro lado, la conceptualización del habitante del desierto como un ser salvaje parece incluso extenderse a la población no indígena. Así, al hablar de los moradores de los ranchos de Tamaulipas, el narrador observa que no hay nada 'que indique que las gentes que viven en esos bosques erizados y solitarios tienen la más [. . .] lejana luz de civilización' (Payno, 1996a: 68). De hecho, la suciedad de sus cuerpos y la falta de sofisticación de sus viviendas hace difícil distinguirlos de los indígenas: 'Se ve uno inclinado a creer cuando pasa una noche en esas chozas sucias y llenas de insectos, que los moradores son más bárbaros que los mismos salvajes del desierto' (68). Para Payno, la devaluación de su aspecto físico es además manifestación de una más grave lacra interior, su indolencia y falta de ambición: 'Los rancheros montan a caballo por las mañanas, [. . .] vuelven a comer su carne asada y a dormir, y a... nada, a estarse ociosos todo el día [. . .] sin imaginar si quiera mejorar sus bienes' (68).

Con todo, es necesario observar que Payno no llega a retratar al nativo en ningún momento como un ser perverso. Su caracterización evoca más bien la de un buen salvaje, es decir, un ser primitivo e inocente que ignora los beneficios de la civilización, pero cuyo carácter intrínsecamente moral lo predispone a recibir las ideas del progreso. De ahí que, al comenzar sus crónicas, el escritor afirme: 'los pueblos de la frontera tienen las más brillantes disposiciones [. . .] y en su carácter naturalmente moral se observan las reliquias de la sencillez de las costumbres de todo pueblo virgen' (Payno, 1996a: 37). En estos textos, el habitante del norte emerge en gran medida como un 'hombre natural', en el sentido que Jean-Jaques Rousseau le diera al concepto en la segunda parte de su influyente Discours sur l'origine et les fondements de l'inégalité parmi les hommes, 1755. Tal y como muestran las citas anteriores, la existencia del habitante norteño, como la del hombre natural, viene determinada por sus necesidades inmediatas (Rousseau, 1820: 75), lo que le motiva a llevar un vida esencialmente física, 'sin movimiento, sin ideas, sin goces, sin ocupación' (Payno, 1996a: 68). Si el hombre natural se caracteriza por 
haber desarrollado una constitución robusta y ágil en su contacto diario con la naturaleza (Rousseau, 1820: 75), el norteño se singulariza repetidamente por mostrar una 'constitución de fierro' y por gozar 'de una salud completa', cualidades que en este caso ha desarrollado como resultado de sus continuas travesías por el desierto (Payno, 1996a: 69). Esta primitiva sociedad de la frontera prueba incluso que la desigualdad no es una característica innata al ser humano, sino un producto de sociedades más avanzadas (Rousseau, 1820: 140-41). De ahí que el escritor insista en retratar el norte como una sociedad sin clases, donde no es posible 'encontrar ese último residuo de la sociedad que se llama plebe', y en la que todos los hombres visten las mismas ropas, comen los mismos alimentos, y 'tienen poco más o menos la misma educación' (Payno, 1996a: 36).

En estas crónicas, la caracterización del habitante fronterizo como un buen salvaje permite al autor suavizar la imagen del norte como desierto improductivo y antiestético que se desprende de su lectura del paisaje norteño. A falta de una naturaleza abundante, Payno encuentra en esta población primitiva pero robusta y bien dispuesta un motivo retórico que justifica la viabilidad de su política respecto al norte, y que puede atraer las simpatías del culto lector capitalino. Un retrato excesivamente negativo de la población no hubiera hecho más que alimentar los numerosos prejuicios existentes sobre la región, y hubiera acabado minando los argumentos del autor en cuanto a la necesidad de mejor integrar estas provincias en el proyecto constitutivo de la nación. No obstante, es necesario recalcar que los atributos positivos que este narrador encuentra en el habitante de la frontera no hacen sino redundar en la representación del norteño como un ser natural o salvaje, es decir, falto del barniz de la educación y la civilización que el interior representa. ${ }^{13}$ La idealización no es sino el reverso de la imagen de barbarie anterior, y no debe entenderse como una contradicción, sino como expresión de la misma mentalidad de apropiación colonial que transformó el paisaje norteño en un desierto cultural y que ahora convierte a sus habitantes en símbolo del atraso cultural, social y económico que el escritor ansía dejar atrás.

Las crónicas de viaje de Manuel Payno sobre el norte deben considerarse textos fundacionales de las literaturas de la frontera, permission has been granted for this version to appear in e-Publications@Marquette. Maney Publishing does not grant permission for this article to be further copied/distributed or hosted elsewhere without the express permission from Maney Publishing. 
pues fijan en el archivo cultural de la nación una imagen contradictoria de la misma que perdura hasta nuestros días: la de un desierto que inspira temor o rechazo al tiempo que se erige en promesa de un nuevo comienzo. En el contexto post-independencia mexicano, la ambivalencia de esta representación nace del intento de imaginar el futuro de la región sirviéndose de un lenguaje que la ancla irremediablemente al pasado colonial, y que la atrapa en las imágenes y metáforas que articularon el proyecto modernizador europeo desde el descubrimiento. Pese al deseo de mostrar el país desde una perspectiva mexicana que anima la aparición de la crónica en México, los textos con los que Payno inaugura este género se hacen eco de una cosmovisión imperialista que proyecta sobre la realidad nacional la misma dinámica excluyente que caracterizó la interacción de las metrópolis europeas con sus colonias. Para Payno, viajar por el norte representa un acto simbólico de incorporación mediante el que la realidad local se subordina a los dictados de la civilización y del progreso. La descripción literaria de tierras y personas se convierte así en una forma de colonizar la frontera, es decir, una manera de conferir orden y llenar de sentido aquello que se percibe como vacío o salvaje, confinándolo al molde de las categorías conceptuales preexistentes.

La representación del norte como escenario de la utopía modernizadora del autor va a relegar además esta región a una posición marginal dentro del imaginario cultural de la nación. Tal y como ocurría en las representaciones coloniales, en estas crónicas el norte se representa como un espacio al margen del progreso. Mas, en este caso, el progreso no sólo emana de Europa, sino que irradia sobre todo desde 'el interior' de la nación. En contraste con las restantes crónicas de tema mexicano escritas por Payno, estos textos no describen parajes sublimes o pintorescos con los que el lector pueda establecer vínculos afectivos o estéticos de pertenencia. A diferencia con otros productos literarios del nacionalismo criollo que se articularon también en torno a la dicotomía barbarie/civilización, en el norte el escritor tampoco encuentra ningún grupo humano, ni ningún individuo, cuyas costumbres despierten su interés, o que puedan acabar sirviendo de base al desarrollo de una identidad nacional auténtica. En el norte mexicano que retrata Payno no hay pampas, ni gauchos, ni Facundos que sirvan de embrión a una eventual permission has been granted for this version to appear in e-Publications@Marquette. Maney Publishing does not grant permission for this article to be further copied/distributed or hosted elsewhere without the express permission from Maney Publishing. 
representación mestiza de la nación. La dicotomía civilización/barbarie que caracteriza otras obras de la época se reconfigura aquí rígidamente como una tensión dialéctica entre el centro y la periferia en la que la capital se erige en el nuevo paradigma de la modernidad, y en la que el norte pasa a identificarse como baluarte del atraso. Sus crónicas se hacen así eco temprano del centralismo político y cultural que va a caracterizar el liberalismo mexicano a lo largo del siglo XX, y revelan las profundas raíces coloniales que el discurso centralista presenta en México.

En 1936, José Vasconcelos definía la frontera en sus memorias como 'un no man's land del espíritu' (1982: I, 554). Más de cincuenta años después Carlos Fuentes reiteraba esta misma idea en el contexto de la globalización, al referirse a la franja territorial que deben cruzar los emigrantes en su camino a los EE.UU. como 'una tierra de nadie' (1992: 513). Las crónicas de Payno sobre el norte nos recuerdan que esta persistente caracterización de la frontera como un desierto entre polos u horizontes de progreso está inextricablemente ligada a la utopía civilizadora que continuó moldeando el discurso cultural mexicano tras la independencia.

\section{Bibliografía}

Anna, T. E. 1998. Forging Mexico. 1821-1835. Lincoln: University of Nebraska Press.

Bowden, B. 2009. The Empire of Civilization: The Evolution of an Imperial Idea. Chicago \& London: The University of Chicago Press.

Cañizares-Esguerra, J. 2006. Landscapes and Identities: Mexico, 1850-1900. En: Nature, Empire and Nation. Explorations of the History of Science in the Iberian World. Stanford, CA: Stanford University Press, pp. 12968.

Carrera, M. M. 2006. Imagining the Nation and Forging the State: Mexican Nationalist Imagery: 1810-1911. En: Travelling from New Spain to Mexico. Mapping Practices of Nineteenth-Century Mexico. Durham \& London: Duke University Press, pp. 109-43.

Clark de Lara, B. 2005. La crónica del siglo XIX. En: B. Clark de Lara y E. Speckman Guerra, eds. La república de las letras. Asomos a la cultura escrita del México decimonónico, * vols. México D.F.: Universidad Nacional Autónoma de México, vol. I, pp. 324-53. permission has been granted for this version to appear in e-Publications@Marquette. Maney Publishing does not grant permission for this article to be further copied/distributed or hosted elsewhere without the express permission from Maney Publishing. 
NOT THE PUBLISHED VERSION; this is the author's final, peer-reviewed manuscript. The published version may be

accessed by following the link in the citation at the bottom of the page.

Crónica. Def. 2. Diccionario de la lengua española. Vigésima segunda edición [en línea] [consultado el 10 de junio de 2012]. Disponible en:http://www.rae.es/rae.html

Fernández de Rota y Monter, J. A. 2004. Los paisajes del desierto. En: H. Salas Quintanal y R. Pérez Taylor, eds. Desierto y fronteras. El norte de México y otros contextos culturales. México D.F.: Plaza y Janés, pp. 21-35.

French, W. E. 2011. Living the Vida Local: Contours of Everyday Life. En: W. $\mathrm{H}$. Beezley, ed. A Companion to Mexican History and Culture. Marlton, MA: Wiley-Blackwell, pp. 13-33.

Fuentes, C. 1992. El espejo enterrado. Madrid: Taurus.

Gerson, D. M. ed. 2003. Paradise Lost? Aspects of Landscape in Latin American Art. Catálogo de la exhibición. Coral Gables, FL: University of Miami.

Giron, N. 1994. Un liberal en tono menor. Historia mexicana, 4(1): 5-35.

Guerrero Aguilar, A. 2007. El noreste mexicano en la obra de Manuel Payno. Revista de Humanidades: Tecnológico de Monterrey [en línea] 022: 13-44 [consultado el 4 de junio, 2012]. Disponible en:< http://redalyc.uaemex.mx/pdf/384/38402201.pdf>

Lidell, H. G. \& Scott R., comps. 1961. Greek-English Lexicon. Oxford: Clarendon Press.

Lomnitz, C. 2001. Deep Mexico. Silent Mexico. An Anthropology of Nationalism. Minneapolis: University of Minnesota Press.

Losada, M. J. 2009. Avatars of a Binary: Civilization and Barbarism from Sarmiento to Contemporary Spain. PhD thesis, University of California, Berkeley.

Mignolo, W. D. 1995. Afterword: Human Understanding and (Latin)American Interests. The Politics and Sensibilities of Geocultural Locations. Poetics Today, 16(1): 171-214.

Mignolo, W. D. 2000. Local Histories/Global Designs. Coloniality, Subaltern Knowledges, and Border Thinking. Princeton, NJ: Princeton University Press.

Payno, M. 1996a. Panorama de México. En: B. Rosen Jélomer, ed. Manuel Payno. Obras completas. Vol. V. México, D.F.: Conaculta.

Payno, M. 1996b. Historia nacional. En: B. Rosen Jélomer, ed. Manuel Payno. Obras completas. Vol. XII. México, D.F.: Conaculta.

Pitman, T. 2008. Mexican Travel Writing. Oxford: Peter Lang.

Pratt, M. L. 1992 Imperial Eyes. Travel Writing and Transculturation. Routledge: London \& New York.

Rajchenberg, E. S. \& Héau-Lambert C. 2009. ¿Wilderness vs. desierto? Representaciones del septentrión mexicano en el siglo XIX. Norteamérica [en línea] 4(2) [consultado el 4 junio 2012]. Disponible en: <http://www.scielo.orh.mex/pdf/namerica/ v4n2/v4n2a2.pdf>

Hispanic Research Journal, Vol 15, No. 4 (August 2014): pg. 302-317. DOI. This article is @ Maney Publishing and permission has been granted for this version to appear in e-Publications@Marquette. Maney Publishing does not grant permission for this article to be further copied/distributed or hosted elsewhere without the express permission from Maney Publishing. 
NOT THE PUBLISHED VERSION; this is the author's final, peer-reviewed manuscript. The published version may be accessed by following the link in the citation at the bottom of the page.

Rousseau, J.-J. 1820. Discurso sobre el origen y los fundamentos de la desigualdad de condiciones entre los hombres. Madrid: José del Collado.

Salas Pérez, M. E. 2005. Costumbrismo y litografía en México: un nuevo modo de ver. México D.F. UNAM.

Segre, E. 2007. Intersected Identities. Strategies of Visualization in Nineteenth- and Twentieth-Century Mexican Culture. New York \& Oxford: Berghahm Books.

Spurr, D. 1993. The Rhetoric of Empire. Colonial Discourse in Journalism, Travel Writing, and Imperial Administration. Durham \& London: Duke University Press.

Truett, S. 2006. Fugitive Landscapes: the Forgotten History of the U.S. Mexico Borderlands. New Haven: Yale University Press.

Vasconcelos, J. 1982. Memorias. 2 vols. México D.F.: Fondo de Cultura Económica.

\section{Notes}

${ }^{1}$ Nueve de las crónicas comprendidas en la serie 'El Río Bravo del Norte' fueron compiladas en 1996 por Boris Rosen Jélomer en su quinto volumen de las obras completas de Manuel Payno. Se trata de 'Matamoros', 'La costa', 'Reynosa y Reynosa Vieja', 'Camargo', 'La tropa veterana. Los soldados de la frontera', 'Jueves Santo en Mier, Revilla, Laredo, Río Grande', 'Geografía de Tamaulipas', 'Sigue el itinerario', y 'La cueva del Carrizal. Lampazos'. Otras dos, 'Una victoria' y 'La rebelión de Tamaulipas, años de 1838, 1839 y 1840', aparecen en el volumen XII, el dedicado a sus escritos de tema histórico. Este artículo se centra en el análisis de las nueve crónicas de viaje, aunque se aludirá a las de tema histórico.

2 Tal y como propone Thea Pitman en su seminal estudio panorámico sobre el género, el término 'crónica de viajes' es el más frecuentemente utilizado por la crítica literaria para referirse al género de la literatura de viajes en México. Para una discusión de los orígenes y usos del término en México, ver Pitman (2008: 32-38).

3 Para un detallado análisis del valor estratégico del río para ambos países ver Guerrero Aguilar (2007: 18-21).

${ }^{4}$ Pitman opone la idea de 'criollización' a la de 'transculturación', concepto ampliamente adoptado por la crítica para el estudio de la literatura de viajes a partir de la publicación de Imperial Eyes, de Mary Louise Pratt (1994). La transculturación se define como un proceso de apropiación crítica y selectiva de materiales transmitidos por la cultura metropolitana dominante por parte de las culturas subalternas (Pratt, 1994: 6). Pitman reconoce que en la crónica de viajes mexicana del

Hispanic Research Journal, Vol 15, No. 4 (August 2014): pg. 302-317. DOI. This article is @ Maney Publishing and permission has been granted for this version to appear in e-Publications@Marquette. Maney Publishing does not grant permission for this article to be further copied/distributed or hosted elsewhere without the express permission from Maney Publishing. 
NOT THE PUBLISHED VERSION; this is the author's final, peer-reviewed manuscript. The published version may be accessed by following the link in the citation at the bottom of the page.

XIX se dan indicios de transculturación, pero matiza que la conciencia crítica que el proceso transculturador revela no se manifiesta con las misma intensidad en todas las obras de la época, sino que más bien depende del temperamento y las ideas políticas del escritor individual (2008: 82-84). Las crónicas de Payno adolecen de conciencia crítica respecto a los modelos imitados, por lo que, siguiendo a Pitman, preferimos considerarlas fruto de la criollización, más que resultado de un proceso autorreflexivo de transculturación.

${ }^{5}$ En Imperial Eyes (1992), Pratt se sirve de la expresión 'the monarch-of-allI-survey' para referirse a la relación de poder que se establece entre observador y observado en la literatura de exploración europea. La expresión utilizada por Spurr para describir esta relación en The Rhetoric of Empire (1993), es 'the commanding view'. Ambos términos aluden casi de forma simultánea a un mismo fenómeno retórico de subordinación, y establecen una clara relación entre paisaje e ideología. La traducción como 'panorámica', un término ampliamente utilizado en español en referencia al paisajismo pictórico o fotográfico, nos parece la más apropiada en este contexto.

${ }^{6}$ Se trata de 'La rebelión de Tamaulipas, años de 1838, 1839 y 1840' (Payno, 1996b, 355-67).

${ }^{7}$ Esta idea se inspira en las propuestas del sociólogo Claudio Lomnizt sobre la obra de Justo Sierra y, en particular, en sus comentarios sobre la visión evolucionista de la historia mexicana que Sierra y su equipo de colaboradores desarrollan en México: su evolución social, obra publicada en tres volúmenes entre 1900 y 1902. Las crónicas de Payno sobre el norte apuntan ya a la visión de la historia mexicana que se consolidará en la segunda mitad del siglo en el trabajo de los denominados científicos' (Lomnitz, 2001, 240-41).

${ }^{8}$ El papel que la descripción de paisajes y costumbres tiene en la formación de la conciencia nacional en el México post-independencia apenas ha sido estudiado por la crítica literaria. Tal y como constata Pitman, no hay ningún estudio que se centre en el costumbrismo mexicano en este periodo, y los estudios sobre paisajismo y literatura resultan hoy anticuados en su aproximación teórica (2008: 38). No obstante, es necesario destacar que el tema ha comenzado a generar una amplia bibliografía en el campo de las artes visuales (pintura, fotografía, ilustración gráfica, etc.). Ver Cañizares-Esguerra (2006), Carrera (2006), Segre (2007), Gerson (2003), y Salas Pérez (2005).

${ }^{9}$ Esta conexión entre estética e ideología es una de las tesis centrales de Pratt al describir la posición de autoridad desde la que escribe el viajero colonial. Según Pratt, las deficiencias estéticas que los escritores europeos encontraron en los paisajes colonizados al compararlos con los de su hogar se convierten en una forma más de justificar la colonización, al sugerir 'a need for social and material intervention by the home culture' (Pratt, 1992: 205).

Hispanic Research Journal, Vol 15, No. 4 (August 2014): pg. 302-317. DOI. This article is @ Maney Publishing and permission has been granted for this version to appear in e-Publications@Marquette. Maney Publishing does not grant permission for this article to be further copied/distributed or hosted elsewhere without the express permission from Maney Publishing. 
NOT THE PUBLISHED VERSION; this is the author's final, peer-reviewed manuscript. The published version may be accessed by following the link in the citation at the bottom of the page.

${ }^{10}$ Los autores desarrollan esta idea en un estudio que contrasta la representación de la frontera en las literaturas mexicana y estadounidense. En él, Rajchenberg y Héau-Lambert analizan brevemente la obra de Payno y ya vinculan 'la distancia emotiva' que el escritor mantiene respecto al paisaje con la representación del norte como desierto que se hereda de la época colonial (Rajchenberg \& Héau-Lambert, 2009).

${ }^{11}$ Para un desarrollo de la idea de desierto como espacio fuera del control y la razón sedentaria ver Fernández de Rota y Monter (2004: 22)

12 El tratamiento de la capital y sus alrededores como paraíso agrícola y cuna de la civilización mexicana es recurrente en sus otras crónicas. Ver, por ejemplo, 'La falda de los volcanes' (Payno, 1996a: 136-40), 'El desierto' (141-44), o 'San Agustín de las Cuevas' (158-61).

${ }^{13}$ No resulta sorprendente que, después de publicadas estas crónicas, Payno se viera obligado a rectificar sus observaciones por el 'disgusto' causado entre los habitantes de la región, según él mismo explica en una nota a pie de página en "El Puerto de Matamoros" (Payno, 1996a: 108). En ésta crónica, de 1944, y en otra que publica en el Museo Mexicano en 1845 y que dedica a la ciudad de Monterrey ("Monterrey") el tono de la descripción del paisaje y las gentes se hace mucho más halagador. 
NOT THE PUBLISHED VERSION; this is the author's final, peer-reviewed manuscript. The published version may be accessed by following the link in the citation at the bottom of the page.

Despite the growing critical interest in Mexican travel literature, very few studies take into account the way in which Mexican writers use the genre to create and define a national identity after independence. This article analyzes 'El Río Bravo del Norte', a series of 'crónicas' published by Manuel Payno which relate his travels in the so-called 'Oriental Provinces' during the years preceding the war with the United States. Echoing the vision of the north as a savage, desert territory that characterized the colonial cultural imagination, Payno depicts the northern border as a land that needs to be domesticated, in order to secure the prosperity and territorial integrity of the young nation. In Payno's chronicles the border becomes the stage for a renewed civilizing mission in which the nation's capital and its elites become the new paradigm of modernity. This essay will focus on the ways in which this utopian mission informs Payno's representation of the history, landscape, and peoples of the north in his travel essays.

KEYWORDS: Manuel Payno, Mexican travel literature, nineteenth-century Mexican literature, border literature, Mexican landscape, Mexican customs

\section{[Nota sobre la autora]}

Pilar Bellver is Associate Professor of Spanish at Marquette University. Her specialization is U.S. Latino/a literature and Border Studies, with an emphasis on Mexican literature on the border. Her latest research brings to critical attention a number of texts which turn the description of the more remote and desert landscapes of the region into a reflection on cultural identity within the framework of Mexican national discourse. Articles on this topic have appeared previously in Confluencia and Hipertexto. 